\title{
New England Census Division
}

National Cancer Institute

\section{Source}

National Cancer Institute. New England Census Division. NCI Thesaurus. Code C76338.

A census division of the United States consisting of Maine, New Hampshire, Vermont, Massachusetts, Rhode Island, and Connecticut. 